\title{
Current perspectives on the ethics of selling international surrogacy support services
}

This article was published in the following Dove Press journal:

Medicolegal and Bioethics

\author{
Patricia Fronek ${ }^{1,2}$ \\ 'Law Futures Centre, ${ }^{2}$ School of \\ Human Services and Social Work, \\ Griffith University, Southport, QLD, \\ Australia
}

\begin{abstract}
This review presents current knowledge on selling surrogacy support services in developing countries. Rather than focusing on dichotomous positions, ethical issues that are present and unresolved are discussed by following the journey of surrogate mothers and highlighting the position of children whose well-being is generally assumed in surrogacy arrangements. Ethical concerns about conflicts of interest, fundamental freedoms, autonomy, informed consent, self-determination, privacy, and protecting children are shared across countries. International commercial surrogacy is predicated on profit made by service providers and intermediaries where producing a healthy, desired child for the consumer of services is the goal. As such, business models conflict with the well-being of women and children. Selling international surrogacy support services presents complex and multi-layered problems that must be understood in the context of a growing body of knowledge to ensure ethical deliberations are not based on fallacious premise or assumed propositions. International surrogacy is not a level playing field. Would-be parents and practitioners need the information and the opportunity to grapple with ethical issues when considering surrogacy arrangements, or enabling or profiting from it.
\end{abstract}

Keywords: international commercial surrogacy, ethics, children, surrogate mothers

\section{Introduction}

International commercial surrogacy (ICS) is a practice where commissioning parents in one country directly or indirectly hire a woman in another country to bear a child on their behalf. Various combinations of commissioning parents, intermediaries (facilitators, agents, brokers, and recruiters), doctors and clinics, lawyers, donors, and surrogate mothers come together to produce a desired child. ${ }^{1-3}$ Estimating its prevalence and global worth is severely hampered by differences between countries and the lack of any robust statistics and reporting mechanisms. Using India where ICS is a multi-billion dollar industry and the international medical market place as a gauge, the actual profit made would be significant. ${ }^{4-7}$ In many countries, ICS is an underground activity, often a secret in plain sight. Whether motivated by a desire to have a family, to profit from the arrangement, to help others, or to earn an income, it is not uncommon for individuals and businesses to work around laws or to break them to achieve a successful surrogacy. In terms of regulation, countries are permissive, unregulated, or ban its practice entirely. ${ }^{8}$ Governments in the countries of commissioning parents respond reactively to complex problems with immigration, citizenship, parenting, and parentage, calling on children's best interests' principle reflected in the UN's Convention on the Rights of the Child, Article $3 .{ }^{9}$ In jurisdictions where it is illegal
Correspondence: Patricia Fronek School of Human Services and Social Work, Griffith University, Southport, Gold Coast Campus, Parklands Drive, Southport, QLD 4222, Australia

Tel +6I 755529345

Email p.fronek@griffith.edu.au 
for citizens to commission an ICS arrangement in another country, governments do not prosecute.

There are arguments that support and oppose ICS; however, on a global scale, the "can do" has long overtaken the "should we". Because the horse has long bolted and ICS is firmly entrenched, current international perspectives concerned about protecting the vulnerable and exploited and upholding children's rights tend to lean pragmatically toward international regulation. ${ }^{8,10}$ As countries regulate and limit who can access surrogacy services or ban it entirely, businesses move to less regulated countries where they can practice without government interference while providing a service to all comers.

Asia, specifically India, has been a popular destination for ICS since 2002 and is the most researched. ${ }^{11}$ Although its lucrative industry is regulated, it thrives with minimal oversight supported by government as a part of the health tourism sector. Surrogacy clinics that provided services to same sex couples in India relocated to Thailand, Cambodia, and Nepal following the introduction of restrictive legislation in 2013. Women are transported across borders to maintain these businesses, for example, Indian women to Nepal and Cambodian women to Thailand. Thailand, previously unregulated, banned surrogacy in response to international scandals. Mexico introduced regulation in 2015, and the Cambodian government is developing new legislation after imposing a temporary ban in effect until 2018. Businesses have again shifted, and Laos has become the latest Asian hot spot for unregulated ICS. The Ukraine and Russia remain popular European destinations, while Poland, Romania, Georgia, Dubai, Iran, and Lebanon are other emerging hotspots. ${ }^{12}$

The rapid shifts from country to country make empirical research on commercial surrogacy in these countries challenging. Clinics and agents often control access to surrogate mothers, and women can be reluctant to engage with researchers due to changes in laws, financial dependence on clinics and agents, and concerns about their privacy. Many experience shame and stigma in their culture and communities or have experienced invasion of their privacy by the media seeking stories where scandals erupt. Consequently, the majority of studies on ICS are small, qualitative studies that do provide valuable insights. Although findings from these studies cannot be generalized from country to country, there is a sufficient body of research to show that an array of ethical problems exist wherever ICS is practiced. ${ }^{2,8,13-16}$

In many countries, women are subjected to power differentials inherent in marked social disparities and chronic economic deprivation. These conditions create particular vulnerabilities in surrogacy arrangements compared to the wealthier consumers of these services. The circumstances of surrogate mothers' impacts on children's health and their rights. The children have the right to know information formative to their identities, that is, specifically their origins and relationships. ${ }^{9}$ Child protection concerns related to children born of surrogacy are too often dismissed as exceptional cases when scandals are reported because the well-being of children is generally assumed. ${ }^{17,18}$ To address the urgent need for national and international child-focused responses to surrogacy arrangements, International Social Service (ISS) Geneva has brought together a group of international experts on surrogacy. The group is working with states, nongovernment organizations, and academic institutions that include among others the Permanent Bureau of the Hague Conference on Private International Law and the UN Special Rapporteur on the Sale and Exploitation of Children and UNICEF. ${ }^{19,20}$

This review explores the ethics of selling ICS services that have not been satisfactorily addressed in regulation or practice, in particular those concerns that impact on surrogate mothers and children in developing countries. As such, this review does not offer arguments in support or against ICS rather evaluates the ethics of selling ICS support services against existing knowledge.

\section{A word on language}

A number of interesting shifts have occurred in public discourse, laws, and the scholarly literature in relation to the language used to describe ICS, pertinent because language does influence perceptions. ${ }^{21}$ "Commissioning parents" has been replaced with "intending parents" creating a semantic distinction that separates would-be parents from the financial nature of ICS arrangements but fails to change the underlying economic dynamic. "Mother" is often removed from "surrogate mother" allowing greater objectification, even though the surrogate mother is the biological, and in most countries, the legal mother at birth regardless of genetic relatedness or contracts. In 2017, an international glossary proposes "cross border reproductive care" as the preferred term for "the provision of reproductive health services in a different jurisdiction or outside of a recognized national border within which the person or persons legally reside". ${ }^{22}$ Views on these semantic shifts range from concerns about manipulating perceptions and presenting a more benign image to facilitate communication through language that is more acceptable to some stakeholders. ${ }^{21}$

ICS is commonly described as a fertility treatment. When defined so simply, genetic relationships between the child 
and usually one commissioning parent are given primacy over other donors and the physiological relationship with the surrogate mother. Reducing ICS to a fertility treatment alone simplifies the complex reality that ICS is also a social, psychological, legal, and financial phenomenon that requires the bodies of one or more strangers and multiple paid intermediaries and providers who sell their services. ${ }^{23}$ The network of financial and social transactions without which ICS arrangements could not occur is considered nonconsequential. By ignoring the other domains, ethical concerns about surrogate mothers and children and role of profit can more easily be dismissed, rationalized, or minimized.

The choice of language in this review is intentional, not to cause offense to any stakeholder but to accurately reflect the business nature of ICS, the status of surrogate mothers and children, and to distinguish ICS from other forms of surrogacy not addressed in this review.

\section{Surrogate mothers}

Ethical concerns about fundamental freedoms, autonomy, self-determination, privacy, confidentiality, and informed consent as they relate to surrogate mothers can be explored by following their journey through ICS arrangements starting with recruitment.

\section{Recruitment}

Women who sell their eggs and become surrogate mothers in Asia, South America, Europe, and Africa usually live in impoverished conditions. Existing research indicates that coercive practices whether by poverty or persons does exist in ICS.

Relieving chronic financial distress by providing an income source is generally reported to be a motivating factor for Indian surrogate mothers. Some women are inspired by media stories and some are reported to enter arrangements of their own accord. ${ }^{2,24}$ Of greater concern are the multiple reports of coercion by brokers, in-laws, and husbands., 2,5,25-27 Agents are known to be hired by doctors, husbands, or relatives. ${ }^{28}$ In these situations, women experience no agency over the decision to become a surrogate or the recruitment process. These experiences begin an ongoing dynamic that continues to erode their autonomy and any capacity for self-determination.

Indian women are first introduced to surrogacy as egg donors to test their tolerance for medical procedures before entering a surrogacy arrangement. To maintain this income, women sell eggs between surrogacies or are engaged as local recruiters when they are no longer suitable as a surrogate, locking women into a prolonged dependency cycle for the period of time that they are useful. ${ }^{2,3,28}$ Local recruiters present a positive view of surrogacy to potential surrogate mothers despite any negative health, social, or psychological effects that they themselves may have experienced. ${ }^{28}$ This dynamic limits their capacity to deviate from the script, and "cycles of dependence and inequality" are perpetuated. ${ }^{3}$

Women, often uneducated and illiterate, are evaluated for their suitability as surrogates, that is, their likelihood of handing over the child. Assessment is about ensuring the success of the commissioned surrogacy not about the interests or well-being of the woman. Saravanan ${ }^{27}$ described the preference for passive women in selection processes and how those women considered "aggressive" and more likely to assert their opinions are rejected. Where psychological testing is utilized, the focus is on eliminating psychopathology and excluding factors that have the potential to disrupt the progress of surrogacy arrangements rather than on the short- and long-term health and psychosocial well-being of surrogate mothers. ${ }^{29}$

Agents and clinics control every aspect of women's lives at home or in institutions where women stay for the duration of their pregnancies to avoid the negative consequences of stigma within their communities and where pregnancies can be monitored. To provide a service to commission parents and to ensure the desired outcome, clinics along with agents control behavior and limit the freedom of surrogate mothers. Shop keepers are instructed about what can be purchased, agents' dispense medication, and use psychologically manipulative techniques such as creating rivalry between women to control them. ${ }^{2}$ Pande $^{2}$ described complicated and nuanced power dynamics where women offer resistance, but ultimately they had less power than intermediaries, clinics, and commissioning parents.

In Thailand, two groups of surrogate women are reported, those who advertise on Internet notice boards and those recruited by agents..$^{30,31}$ The women who advertised in Hibino and Shimazono's study were in desperate financial positions. Their compensation was intended to resolve intractable financial problems such as funding a parent's dialysis, paying off debt, or feeding or educating their families. ${ }^{31}$ Although they appeared to have greater agency in the surrogacy process, these women still expressed struggles with the process. ${ }^{31}$

The second group of Thai women was recruited by agents. They were extremely poor and vulnerable as they had little understanding of surrogacy and its implications. ${ }^{30}$ Buddhist philosophies and cultural elements posed an additional layer of influence in Thai surrogacies. ${ }^{30-32}$ Women made sense of 
their surrogacies through Tan-bun, a "meritorious and good act", that compensates for bad deeds in this life and provides merits for the next. ${ }^{30,31}$ Helping others and doing good are meritorious acts that make engaging in surrogacy and any suffering that might come with it acceptable if not desirable. Cambodian culture shares the Buddhist philosophy of meritorious acts with Thailand. A study currently underway in Cambodia by the author and colleagues confirms that even with culturally embedded altruism, adverse financial circumstances are a coexisting precondition. Communities where poverty and gambling debt are rife were the source of Cambodian surrogate mothers prior to its ban.

In India, altruistic language used by clinic staff, agencies, and intermediaries about doing good deeds encourages women to suppress their own needs to ensure the completion of a successful surrogacy. ${ }^{3,28}$ Altruistic motivations are projected on to them. Karandikar et $\mathrm{al}^{28}$ found that Indian women used the Hindi word "majburi" translated to mean compelled, obligated, constrained, and helpless due to overwhelming life conditions. Majburi does not reflect personal decision making and women do not embrace agency or choice. Instead they accept that in their economically desperate state, God has made the decision for them. ${ }^{1,33}$ Meritorious acts and altruism function as moral justification and as suggested that their innate messages are practiced by women using repetitive coping techniques until they are believed.

The discourse of choice is often deemed relevant to women in developing countries. Making a choice is postulated as a feminist act in its own right because it assumes empowerment by virtue of the woman making her own choice. ${ }^{34,35}$ Choice theory is generally criticized for encouraging individualism and consumerism while ignoring the impact of race, class, and socioeconomic status, which exacerbates existing power imbalances rather than redressing them. ${ }^{34,35}$ ICS research offers evidence that counters choice arguments. The concept of choice is criticized as superficial and dismissive of the nuances of the circumstances of poor women in developing countries and that paring down to choice validates the dependency cycle created. ${ }^{1}$ Presupposing parallel experiences between already empowered and well-resourced women and those women unable to exercise their most basic human rights will miss the opportunity to truly understand the experiences of surrogate mothers in developing countries and to critically evaluate the state of ethics in ICS.

\section{Informed consent}

Deonandan et $\mathrm{al}^{26}$ highlight that business ethics, not medical ethics, apply in ICS and, as such, are insufficient to fully meet health obligations and ethical standards. They assert that within a business framework, users of ICS services assume the well-being of surrogate mothers, which is not the priority for providers outside producing healthy babies. Health is only considered when the pregnancy or baby is affected.

From a medical perspective, informed consent is defined as consent that ensures a full understanding of all risks and benefits prior to agreeing to a procedure. ${ }^{26}$ The reality of ICS shows a vastly different standard of medical consent exists in ICS than is used in other health care settings. Existing research has identified that informed consent as it is medically understood really does not exist in Indian ICS and that women do not understand the procedures performed on them or their associated risks. ${ }^{36,37}$ Kirby $^{38}$ refers to tradeoffs and questions whether consent can be freely given when the will of others and desperate circumstances compels participation.

Problems with informed consent are not limited to India and are also reported in Thailand, Mexico, and the Ukraine. ${ }^{2,3,12,26,28,29,36-41}$ In these countries, an initial cursory explanation is given to women about surrogacy and legal contracts. This constitutes predetermined legal and medical consent. Reports indicate that uneducated, poor, and often illiterate women do not fully understand medical or legal information, that the information provided on one occasion is limited and that women are not informed of their rights such as withdrawing legal and medical consent. Combs mounts the argument that surrogate mothers do not give fully informed consent for two reasons. First, he highlights that in order to make informed decisions, surrogate mothers need to understand what they are agreeing to in the first place and that the power imbalance inherent in contracts undermines the ability to negotiate with regard to present and future effects of the surrogacy arrangement. Second, he stresses surrogate mothers' inability to predict ensuing events in the coming months that might impact on their original consent, particularly if the initial understanding was limited. ${ }^{41}$

Where women are involved in consent processes, they are expected to sign or place their mark on documents that do not uphold their basic rights and that they believe to be binding. In Mexican contracts, surrogate mothers were required to agree to the condition that they could not choose to have an abortion but must submit to an abortion at the request of commissioning parents. ${ }^{40}$ Women in some countries have no direct involvement in any paperwork, and husbands are required to sign. Women have no access to independent legal or social support or second medical opinions. In these situations, their capacity to make future decisions during an entire pregnancy, birth, and relinquishment is questionable. 
Surrogate mothers undergo multiple medical procedures to achieve a successful surrogacy including the administration of medication, multiple embryo transfers, fetal reductions, sex selection, abortions, and cesarean sections. The literature indicates that these procedures are conducted without providing full explanations of the risks prior to each invasive and noninvasive procedure. In the Ukraine, there are no restrictions on genetic testing or sex selection on preimplantation embryos. ${ }^{41}$ The ethics of sex selection and fetal reductions are long debated. ${ }^{42,43}$ Concerns about sex selection center on gender issues, discrimination, and the impact on family and society versus arguments that are pro individual choice. ${ }^{43}$ Ethical arguments about fetal reductions have developed from a focus on life and death to manage the gray areas using the proportionality principle. ${ }^{44}$ However, when one considers the available evidence in ICS, multiple embryo implantation is purposeful and commonplace and is likely to occur without the surrogate mother's informed consent about how many embryos are implanted, health risks to herself, to the fetuses, or to the child or children born, and the potential that the procedure may be performed. As such, ethical concerns begin long before fetal reduction is actually performed. Deonandan et $\mathrm{a}^{26}$ suggested that multiple pregnancies are cost saving measures to reduce the number of attempts and to ensure a successful pregnancy.

Risks to the woman's health such as hypertension, preeclampsia, cholestasis, hyperemesis gravidarum, venous thromboembolism, and short- and long-term complications from cesarean sections are also not explained ${ }^{45-47}$ Health risks associated with egg donation such as ovarian hyperstimulation syndrome, and alternating surrogate pregnancies and egg donations are also generally not explained.

\section{Social consequences}

Regardless of the reasons that bring women to ICS, there are social consequences of surrogate motherhood. In many societies, women are subjected to stigma and discrimination if their surrogacies become known. Women in India can be accused of adultery, and in some cases, families are forced to move elsewhere after the surrogacy losing connections with their extended families and communities, which is important to survival and social support. ${ }^{28}$ In some regions, large sections of communities have been recruited into surrogacy, which changes the cultural fabric of the community. Where coercion by husbands or other family members exists, women are likely to have little control over the compensation paid or benefit from it and are likely to be vulnerable to repeat involvement through coercion.
The impact on surrogate mothers' families has not been a strong research focus. In many cases, relationships with husbands and children are disrupted when women are housed in hostels or are relocated to other countries. Karandikar et $\mathrm{a}^{48}$ draw attention to surrogate women's concerns about their physical and mental health and the well-being of their own children. Women are unable to attend to the parenting and development needs of their children (usually young) who experience disrupted attachment. Parenting and daily household tasks need to be undertaken by someone else in her absence. ${ }^{27,28}$ When women are moved away from their communities, families are often unable to visit and when they do some clinics have strict visiting rules and do not allow touching between the woman and her children. ${ }^{27}$ When women do remain at home, they are advised to cease sexual relationships with their husbands. How being a surrogate mother affects the marital relationship, particularly where the husband is reluctant or abusive remains unexplored. The social and financial impact on the family is considerable if the woman suffers short- or long-term health consequences including death, which has occurred.

\section{After the birth}

Opportunities for surrogate mothers to change their minds about the surrogacy arrangement are anticipated and carefully eliminated over the course of an ICS arrangement. Few women have the resources to challenge the course set for them if they wished to do so. There is little information to assume that surrogate mothers are different to any other woman who gives birth. Although they might resist, many women do bond with their babies and few are offered the opportunity to make informed decisions about relinquishment after birth and at the time of transfer especially where power disparities are marked. ${ }^{27}$ On the other hand, some women describe emotional detachment from the fetus during pregnancy and the baby once born. To self-protect and guard against future loss, Indian women report focusing on the payment and the benefits to their families. Thai women also engage in considerable self-talk, repeatedly telling themselves that the child does not belong to them. In Thailand, women do not want to use their own eggs because they feel that this would strengthen the biological link while women in India found racial differences between themselves and the baby helped them create emotional distance. ${ }^{30,49}$ This suggests that rather than the absence of emotional attachment and a clear separation in the minds of surrogate mothers, a range of strategies are used to manage emotional attachment. There is usually no short- or long-term counseling available 
to surrogate mothers. Health care ceases after the completion of the transaction.

There is a heavy emphasis on the primacy of genetic relationships that favors commissioning parents (of which only one may be genetically related). Genetic relationships with donors and biological relationships with the surrogate mother are not considered relevant. This understanding is not necessarily universally shared. For example, the sharing of blood between the mother and fetus may be a more meaningful relationship in the surrogate mother's culture than genetic connections. ${ }^{50}$ From a western biomedical perspective, Oxman ${ }^{51}$ provides a detailed, medical explanation of the physiological relationship between a surrogate mother and the child where no genetic relationship exists, in particular the impact on fetal growth and development. He identifies that "there is no organ system of the fetus that is not anatomically, psychologically, and genetically affected by a gestational mother's endocrine system, and therefore, the resulting child is uniquely a product of the gestational mother regardless of who contributed genetic material to the child". He asserts that even from a western medical perspective, this relationship cannot be denied as the child is a product of the gestational relationship. Recognizing both the emotional and physical relationships is important to understand the experience of surrogate mothers and children. Practices such as commissioning parents being present at the birth, surrogate mother's agency in choosing commissioning parents, and the health implications of children being removed at birth to avoid bonding needs to be explored when the needs and rights of women and children and ethical practices are fully considered.

\section{Children born of surrogacy}

Children are the most vulnerable in ICS arrangements. Ethical and legal concerns are raised in relation to the actions of adults that jeopardize children's rights to citizenship and parentage, failures to protect children, and the role of money.

Providers and commissioning parents have taken advantage of the absence of regulations, broken laws, or circumvented them to force governments to act on their behalf. ${ }^{12,52}$ These actions are justified as an active protest against injustice and discriminatory laws and the right to parent that does not exist in international law. Unfortunately, the consequences of these actions have negatively impacted on children who have been left stateless, unable to leave their countries of birth for extended periods, and unable to enter the country of the commissioning parents leaving unresolved citizenship and parentage issues. ${ }^{8,53}$ Although important, the main focus on meeting the interests of children has been on resolving these legal problems after they have been created. The ethics of actions that create children who will be subjected to these risks has attracted little ethical debate. Obtaining a child at any cost and perceptions that the desire to parent is an uncontrollable force that must be satisfied has become normalized with some help from celebrities and the media. ${ }^{54}$ The desire for family and genetic connectedness engenders public sympathy, thereby excusing or justifying ill-considered or defiant actions. In countries where it illegal for commissioning parents to engage in ICS, there have been no prosecutions on the basis of the best interests of the child. The essence of what makes these actions distinct from any other offense committed by parents who are not protected from a range of consequences remains undebated. Intermediaries who host "how to events" in the countries of commissioning parents and legal and medical professionals are indispensable in initiating and completing this precarious process that risks the basic rights and well-being of children born in ICS arrangements.

In ICS, the interests and well-being of children are assumed to be assured in the care of commissioning parents. Although likely to be the case for the majority of commissioning parents, there is a dearth of research in this area to confirm or otherwise. Many more commissioning parents abandon children in their country of birth when their circumstances change or children born do not meet expectations than surrogate mothers who change their minds. ${ }^{41}$ There is no preparation or screening of commissioning parents. The focus is always on the evaluation of surrogate mothers to ensure compliance. If one accepts the argument that abuses of children born to surrogacy are rare and therefore need not impact on the way ICS is currently practiced, one still has to justify whether a system that does not protect even one child is adequate. The truth is we do not know how many children born to surrogacy have become abused children. For example, there are known pedophiles in Israel and Australia who have custody of their surrogate child and others, who are now in prison. ${ }^{17,23}$ In the disputed Baby Gammy case, David Farnell, a convicted pedophile with a preference for girls, and his wife brought a baby girl home and left an unwanted twin, a boy with Down's syndrome, in Thailand. ${ }^{25,29}$ Baby Gammy and the case of the Mitsutoki Shigeta who was investigated for human trafficking and child exploitation fathered 16 children with 11 surrogate women precipitated the banning of surrogacy arrangements in Thailand. ${ }^{15}$ Some children have been subjected to years of abuse. ${ }^{17}$ It is naive to assume that ICS has not been used more widely for the explicit purposes of child abuse. 
There are more cases of concern where children with disabilities or "extra" children are rejected and commissioning parents who separate or change their minds refuse to accept parental responsibility. The fate of children abandoned in their country of birth is generally unknown and is often left to agents to resolve. In countries where there are welldeveloped child protection systems, there is no risk threshold that allows an acceptable number of abused children and the abuse of even one child triggers intensive reviews of practice. In the absence of international regulation, intercountry co-operation, and developing, monitoring, and maintaining standards, any well-resourced person can commission a surrogate without at minimum police checks or suitability assessments.

\section{The question of money and conflicts of interest}

Legal questions exist as to whether an ICS arrangement constitutes the sale of children, which violates children's rights and whether enforcing contracts violates the human rights of surrogate mothers who have lesser capacity to act on their rights even if bestowed. ${ }^{55,56}$ Regardless, these concerns and views that consider children are treated as commodities or property in these commercial transactions juxtapose arguments that ICS is merely a fertility treatment. ${ }^{38,49}$ Surrogate motherhood has been described as "a disaggregated process, where different components are mobilized to achieve the commissioned outcome [...] and is becoming increasingly commodified". 57

Although ICS has been offered as a humanitarian act that functions to lift women out of poverty, the discourse of altruism functions to mask the interests and objectives in the surrogacy industry. ${ }^{1,49,58}$ In a legal sense, the "commercial" in surrogacy is defined by compensation to the surrogate mother. A distinction is made in this review between profit made by service providers and compensation. In ICS, the term compensation could be viewed as a misnomer as amounts received fall short of any real compensation for the surrogacy, its social impact, and its short- and long-term effects. In all countries, little is known about whether long-term financial benefits for surrogate mothers and their families are realized and there is some evidence that even short-term benefits are minimal in developing countries. Surrogate mothers may only be paid after the transfer of a healthy child, do not always get the compensation promised, or do not get paid at all if a child is born with a disability. Some clinics guarantee a full refund to commissioning parents if the surrogate fails to get pregnant which by implication means, the surrogate mother does not receive the promised compensation. ${ }^{49}$ Women may have little control over how their compensation is spent because it may be controlled by other family members or swallowed by debt.

ICS is predicated on profit where producing a healthy, desired child is a necessary element. Profit made by providers of services is crucial to understand ICS and the ethical concerns that arise from its practice. Although individual, private arrangements are made, ICS on the most part involves global networks that cross borders and sectors particularly that of health and tourism. Businesses showcase ICS to potential consumers, such as lawyers, doctors, clinics, and hospitals, and other intermediaries who work together with commissioning parents to ensure a successful surrogacy. ${ }^{2}$

The main professions involved in ICS are legal and medical. The oath of the revised World Medical Association Declaration of Geneva states that the health and well-being of the patient is the first concern, not to use medical knowledge to violate human rights, and includes mentions on privacy, autonomy, and dignity. ${ }^{59}$ The International Bar Association Principles on Conduct for the Global Legal Profession includes conflicts of interest in the 10 core values. ${ }^{60}$ The Convention on the Rights of the Child and the Declaration of Human Rights are also important considerations. ${ }^{9,61}$ Although these rights, values, and principles can be interpreted in a variety of ways, they need to be seriously considered in the practice of ICS where conflicts of interest, in particular, are rarely acknowledged or addressed. Several sources of conflict exist in ICS between the financial interests of professionals, agents, and other intermediaries and the psychological and health needs of surrogate women and between these same financial interests and the best interests of children. The interests of surrogate mothers and children can also compete with those of commissioning parents. A successful surrogacy and the profit it attracts are the strong driver and the bias toward self-interest whether conscious or unconscious is pervasive when unchecked by external monitoring. Conflicts of interest and a lack of transparency will persist as long as ICS is left to market forces, and screening and assessments are conducted by service providers who claim to be able to simultaneously meet the goals of commissioning parents, surrogate mothers, and children.

\section{Conclusion}

While this review has focused on the ethics of selling international surrogacy support services in developing countries particularly the ethical issues involving surrogate mothers and children, it must be acknowledged that commissioning parents are at risk of financial abuse, fraud, and dashed hopes 
in unregulated countries. However, the balance of power in surrogacy arrangements lies with commissioning parents and the many players who work together to achieve a successful surrogacy. When it comes to ICS, we need to flip the script and consider ICS in terms of the well-being of children and surrogate women not from that of brokers, intermediaries, professionals, and commissioning parents who benefit from disadvantage. No matter how it is marketed, ICS is not ethically neutral, and harm has been perpetrated on children and surrogate mothers. Ethical concerns are wide and far reaching. Current approaches and lack of global action fail to incorporate even basic ethical considerations of human dignity and worth into business practices.

The complexities of ICS raise difficult ethical quandaries. When ICS is viewed through a vested interest lens or a particular philosophical position, the minimization of ethical concerns and the rationalization of harmful practices do occur. Stakeholders are at risk of a certain kind of ethical blindness that seems to accompany ICS whether this concerns conflicts of interest, the assumed well-being of children, and assumptions that surrogate mothers always have the freedom to choose. ICS is not a level playing field. Ethical blindness perpetuates a silence that denies commissioning parents and some practitioners the information needed and the opportunity to grapple with ethical issues when considering ICS arrangements and enabling or profiting from it.

A human and child rights approach to the problems in ICS is gaining traction. A rights approach is important, and these rights should be upheld. However, a rights approach is not without its challenges as rights do conflict. Future international instruments and practice guidelines have the potential to curtail unregulated practices and extreme abuses as countries sign and ratify. However, as with other conventions concerning children, international instruments can also morph into facilitating tools in these attempts. ${ }^{62}$

ICS offers hope to those experiencing infertility, are at medical risk during pregnancy, are socially infertile, or simply have made a lifestyle choice not to carry a child. Even so pursuing actions based on these reasons without ethical consideration is flawed. Adopting a consequentialist approach, which can loosely be conceptualized as justifying the means by the end result, requires a rational decision-making process, which to be valid should eliminate any fallacious premise or assumed proposition, incorporate existing knowledge, and consider the structural as well as individual implications. The political, legal, and social institutions form the structures of society that shape advantage and disadvantage and as such bring social justice issues to the fore. It has been argued that consequentialism should determine the lesser evil as well as the greater good, which infers a process, which questions whether individuals should profit at the expense of others by an action that need not be taken. ${ }^{63}$

No matter which position is taken, ICS practices as they stand are ethically unsatisfactory. Governments, middlemen, and professionals who reap considerable financial benefit and people who desperately want a genetically related child can no longer be ignorant of the consequences of this market in its present state. It is a perfect storm brewing for the next international scandal.

\section{Disclosure}

The author reports no conflicts of interest in this work.

\section{References}

1. Bailey A. Reconceiving surrogacy: toward a reproductive justice account of Indian surrogacy. Hypatia. 2011;26(4):715-741.

2. Pande A. Wombs in Labor: Transnational Commercial Surrogacy in India. New York: Columbia University Press; 2014.

3. Nadimpally S, Majumdar A. Recruiting to give birth: agent-facilitators and the commercial surrogacy arrangements in India. In: Davies M, editor. Babies for Sale: Transnational Surrogacy, Human Rights and the Politics of Reproduction. London, UK: Zed Books; 2017:65-81.

4. Almeling R. The Medical Market: Sex Cells for Eggs and Sperm. California: University of California Press; 2011.

5. Nadimpally S, Venkatachalam D. Marketing reproduction: assisted reproductive technologies and commercial surrogacy in India. Indian J Gend Stud. 2016;23(1):87-104.

6. Nayak P. The three Ms of commercial surrogacy in India: mother, money and medical market. In: Dasgupta S, Dasgupta SD, editors. Globalization and Transnational Surrogacy in India. Maryland, US: Lexington Press; 2014:1-22.

7. Spar D. For love and money: the political economy of commercial surrogacy. Rev Int Polit Econ. 2005;12(2):287-309.

8. Trimmings K, Beaumont P, editors. International Surrogacy Arrangements: Legal Regulation at the International Level. Oxford: Hart Publishing; 2013.

9. United Nations [webpage on the Internet]. Convention on the Rights of the Child 1989, Articles 2 and 8. 2017. Available from: http://www. ohchr.org/EN/ProfessionalInterest/Pages/CRC.aspx. Accessed November 10, 2017.

10. Cheney KE. Preventing exploitation, promoting equity: findings from the international forum on intercountry adoption and global surrogacy 2014. Adopt Foster. 2016;40(1):6-19.

11. Chang M. Womb for rent: India's commercial surrogacy. Harvard Int Rev. 2009;31(1):11-12.

12. Saravanan S. Addressing global issues in surrogacy. In: Sill ES, editor. Handbook of Gestational Surrogacy. International Clinical Practice and Policy Issues. United Kingdom: Cambridge University Press; 2016:41-45.

13. Dasgupta S, Dasgupta SD, editors. Globalization and Transnational Surrogacy in India: Outsourcing Life. UK: Lexington Books; 2014.

14. Davies M, editor. Babies for Sale: Transnational Surrogacy, Human Rights and the Politics of Reproduction. London, UK: Zed Books; 2017.

15. Rotabi KS, Bromfield NF. From Intercountry Adoption to Global Surrogacy: A Human Rights History and New Fertility Frontiers. Abingdon, Oxon: Routledge; 2017.

16. Sills ES, editor. Handbook of Gestational Surrogacy: International Clinical Practice and Policy Issues. United Kingdom: Cambridge University Press; 2016. 
17. Fronek $\mathrm{P}, \mathrm{Crawshaw} \mathrm{M}$. The 'new family' as an emerging norm: a commentary on the position of social work in assisted reproduction. $\mathrm{Br} J$ Soc Work. 2015;45(2):737-746.

18. Rotabi KS, Mapp S, Cheney K, Fong R, Mcroy R. Regulating commercial global surrogacy: the best interests of the child. J Hum Rights Soc Work. 2017;2(3):1-10.

19. International Social Service [webpage on the Internet]. Experts Meeting to Discuss International Responses to Surrogacy at University of Verona. 2017. Available from: http://www.iss-ssi.org/index.php/en/ news 1/242-experts-meeting-to-discuss-international-responses-tosurrogacy-at-university-of-verona. Accessed November 10, 2017.

20. International Social Service. Surrogacy: Prohibition, Permission and Protection. Geneva: Monthly Review, No. 212, International Reference Center for the Rights of Children Deprived of the Families, International Social Service; 2017.

21. Beeson D, Darnovsky M, Lippman A. What's in a name? Variations in terminology of third-party reproduction. Reprod Biomed Online. 2015;31(6):805-814

22. Zegers-Hochschild F, Adamson GD, Dyer S, et al. The international glossary on infertility and fertility care, 2017. Fertil Steril. 2017;108(3):393-406.

23. Crawshaw M, Fronek P, Blyth E, et al. What are children's 'best interests' in international surrogacy? A social work perspective from the UK. In: Davies M, editor. Babies for Sale: Transnational Surrogacy, Human Rights and the Politics of Reproduction. UK: Zed Books; 2017 163-184.

24. Huber S, Karandikar S, Gezinski L. Exploring Indian surrogates' perceptions of the ban on international surrogacy. Affilia. Epub October 3, 2017.

25. Deonandan R. Recent trends in reproductive tourism and international surrogacy: ethical considerations and challenges for policy. Risk Manag Healthc Policy. 2015;8:111-119.

26. Deonandan R, Green S, van Beinum A. Ethical concerns for maternal surrogacy and reproductive tourism. J Med Ethics. 2012;38(12): $742-745$.

27. Saravanan S. Transnational surrogacy and objectification of gestational mothers. Econ Polit Wkly. 2010;45(16):26-29.

28. Karandikar S, Gezinski LB, Carter JR, Kaloga M. Economic necessity or noble cause? A qualitative study exploring motivations for gestational surrogacy in Gujarat, India. Affilia. 2014;29(2):224-236.

29. Koert E, Daniluk JC. Psychological and interpersonal factors in gestational surrogacy. In: Sills ES, editor. Handbook of Gestational Surrogacy: International Clinical Practice and Policy Issues. United Kingdom: Cambridge University Press; 2016:70-77.

30. Cohen E. Surrogacy as international business and national disgrace of Thailand. Asian Anthropol. 2015;14(2):115-132.

31. Hibino Y, Shimazono Y. Becoming a surrogate online: "message board" surrogacy in Thailand. Asian Bioeth Rev. 2013;5(1):56-72.

32. Whittaker A. Merit and money: the situated ethics of transnational commercial surrogacy in Thailand. Int J Fem Approaches Bioeth. 2014;7(2): 100-120.

33. Pande A. Not an "angel," not a "whore". Surrogates as 'dirty' workers in India. Indian J Gend Stud. 2009;16(2):141-173.

34. Cakardić A. Down the neoliberal path: the rise of free choice feminism. AM J Art Media Stud. 2014;14:33-44.

35. Thwaites R. Making a choice or taking a stand? Choice feminism, political engagement and the contemporary feminist movement. Femin Theory. 2016;18(1):55-68.

36. Tanderup M, Reddy S, Patel T, Nielsen BB. Informed consent in medical decision-making in commercial gestational surrogacy: a mixed methods study in New Delhi, India. Acta Obstet Gynecol Scand. 2015;94(5):465-472.

37. Tanderup M, Reddy S, Patel T, Nielsen BB. Reproductive ethics in commercial surrogacy: decision-making in IVF clinics in New Delhi, India. J Bioeth Inq. 2015;12(3):491-501.

38. Kirby J. Transnational gestational surrogacy: does it have to be exploitative? Am J Bioeth. 2014;14(5):24-32.
39. Caamano JM. International, commercial, gestational surrogacy through the eyes of children born to surrogates in Thailand: a cry for legal attention. Boston Univ Law Rev. 2016;96(2):571-607.

40. Combs JR. Stopping the baby-trade: affirming the value of human life through the invalidation of surrogacy contacts: a blueprint for New Mexico. N Mex Law Rev. 1999;29(2):407-428.

41. Kindregan CP, White D. International fertility tourism: the potential for stateless children in cross-border commercial surrogacy arrangements. Suffolk Transnatl Law R. 2013;36(3):557-626.

42. Dondorp W, De Wert G, Pennings G, et al. ESHRE task force on ethics and law 20: sex selection for non-medical reasons. Hum Reprod. 2013;28(6):1448-1454.

43. Strange H, Chadwick R. The ethics of nonmedical sex selection. Health Care Anal. 2010;18(3):252-266.

44. Evans MI, Britt DW. Multifetal pregnancy reduction: evolution of the ethical arguments. Semin Reprod Med. 2010;28(4):295-302.

45. Knoche JW. Health concerns and ethical considerations regarding international surrogacy. Int J Gynaecol Obstet. 2014;126(2): $183-186$.

46. Clark EA, Silver RM. Long-term maternal morbidity associated with repeat cesarean delivery. Am J Obstet Gynecol. 2011;205(6 suppl):S2-S10.

47. Silver RM. Implications of the first cesarean: perinatal and future reproductive health and subsequent cesareans, placentation issues, uterine rupture risk, morbidity, and mortality. Semin Perinatol. 2012;36(5):315-323.

48. Karandikar S, Gezinski L, Huber S. Exploring the physical and emotional stress of surrogate pregnancy among transnational Indian surrogates. Int Soc Work. 2017;60(6):1433-1442.

49. Harrison L. "I am the baby's real mother": reproductive tourism, race and the transnational construction of kinship. Womens Stud Int Forum. 2014;47(pt A):145-156.

50. Bos P. Once a Mother: Relinquishment and Adoption from the Perspective of Unmarried Mothers in South India [Ph.D. thesis]. Radboud Universiteit, The Netherlands; 2017. Available from: http:// webdoc.ubn.ru.nl/mono/b/bos_g/oncea_mo.pdf. Accessed November $10,2017$.

51. Oxman RB. Maternal-fetal relationships and nongenetic surrogates. Jurimetrics. 1993;33(3):387.

52. Quartly M, Swain S, Cuthbert D. The Market in Babies: Stories of Australian Adoption. Clayton, Victoria: Monash University Publishing; 2013.

53. Mohapatra S. Stateless babies and adoption scams: a bioethical analysis of international commercial surrogacy. Berkeley J Int Law. 2012;30(2):412-450.

54. van den Akker O, Fronek P, Blyth E, Frith L. 'This neo-natal ménage à trois': British media framing of transnational surrogacy. $J$ Reprod Infant Psychol. 2015;34(1):1-14. Epub 2015 Nov 17.

55. Smart C. The problem with rights. In: Smart C, editor. Feminism and the Power of the Law. New York: Routledge; 1989:138-159.

56. Smolin D. Surrogacy as the sale of children: applying lessons learned from adoption to the regulation of the surrogacy industry's global marketing of children. Pepperdine Law Rev. 2016;43(2):265-344.

57. Van den Akker O. Surrogate Motherhood Families. London: Palgrave Macmillan; 2017:51.

58. Cuthbert D, Fronek P. Perfecting adoption: reflections on the rise of commercial offshore surrogacy and family formation in Australia. In: Hayes A, Higgins D, editors. Families, Policy and the Law: Selected Essays on Contemporary Issues for Australia. Melbourne, Victoria: Australian Government and Australian Institute of Family Studies; 2014:55-56.

59. World Medical Association [webpage on the Internet]. Declaration of Geneva. 2017. Available from: https://www.wma.net/policies-post/ wma-declaration-of-geneva/. Accessed Nov 10, 2017.

60. International Bar Association [webpage on the Internet]. Principles on Conduct for the Global Legal Profession 2011. 2017. Available from: https://www.ibanet.org/Article/NewDetail.aspx?ArticleUid=BC99FD2CD253-4BFE-A3B9-C13F196D9E60. Accessed November 10, 2017. 
61. United Nations [webpage on the Internet]. Universal Declaration of Human Rights 1948. 2017. Available from: http://www.un.org/en/ universal-declaration-human-rights/. Accessed November 11, 2017.

62. Fronek P, Cuthbert D. The future of inter-country adoption: a paradigm shift for this century. Int J Soc Welf. 2012;21(2):215-224.
63. Grisez G. Against consequentialism. Am J Jurispud. 1978;23(1): 21-72.
Medicolegal and Bioethics is an international, peer-reviewed, open access journal exploring the application of law to medical and drug research and practice and the related ethical and moral considerations. The journal is characterized by the rapid reporting of reviews, case reports, guidelines and consensus statements, original research
Dovepress

and surveys. The manuscript management system is completely online and includes a very quick and fair peer-review system. Visit http://www.dovepress.com/testimonials.php to read real quotes from published authors. 